\title{
Therapeutic opportunities for alcoholic steatohepatitis and nonalcoholic steatohepatitis: exploiting similarities and differences in pathogenesis
}

\author{
Thomas Greuter, ${ }^{1,2}$ Harmeet Malhi, ${ }^{2}$ Gregory J. Gores, ${ }^{2}$ and Vijay H. Shah ${ }^{2}$ \\ 'Division of Gastroenterology and Hepatology, University Hospital Zurich, Zurich, Switzerland. ${ }^{2}$ Gastroenterology Research \\ Unit, Division of Gastroenterology and Hepatology, Mayo Clinic, Rochester, Minnesota, USA.
}

Alcoholic steatohepatitis (ASH) and nonalcoholic steatohepatitis (NASH) are among the most frequent causes of chronic liver disease in the United States. Although the two entities are triggered by different etiologies - chronic alcohol consumption (ASH) and obesity-associated lipotoxicity (NASH) - they share overlapping histological and clinical features owing to common pathogenic mechanisms. These pathogenic processes include altered hepatocyte lipid metabolism, organelle dysfunction (i.e., ER stress), hepatocyte apoptosis, innate immune system activation, and hepatic stellate cell activation. Nonetheless, there are several disease-specific molecular signaling pathways, such as differential pathway activation downstream of TLR4 (MyD88-dependence in NASH versus MyD88-independence in ASH), inflammasome activation and IL-1 $\beta$ signaling in ASH, insulin resistance and lipotoxicity in NASH, and dysregulation of different microRNAs, which clearly highlight that ASH and NASH are two distinct biological entities. Both pathogenic similarities and differences have therapeutic implications. In this Review, we discuss these pathogenic mechanisms and their therapeutic implications for each disease, focusing on both shared and distinct targets.

Conflict of interest: The authors have declared that no conflict of interest exists.

Reference information: JCI Insight. 2017;2(17): e95354 https://doi.org/10.1172/jici. insight.95354.

\section{Introduction}

Alcoholic liver disease (ALD) and nonalcoholic fatty liver disease (NAFLD) are among the most frequent causes of chronic liver disease in the United States $(1,2)$. Pathologically, ALD represents a broad spectrum of disorders ranging from simple steatosis to steatohepatitis and cirrhosis. Clinically, patients can be asymptomatic or present with acute severe alcoholic hepatitis (AH) with and without cirrhosis. ALD is caused by chronic alcohol consumption, with commonly reported cutoffs of 40 to $80 \mathrm{~g}$ ethanol per day for men and 20 to 40 g per day for women (3-6). The term nonalcoholic steatohepatitis (NASH) was coined in 1980, when Ludwig and colleagues described a cohort of middle-aged patients with elevated liver enzymes who had liver biopsy findings consistent with $\mathrm{AH}$, but without a history of alcohol consumption (7). NAFLD is defined as the presence of hepatic steatosis in the absence of factors that cause secondary fat accumulation such as significant alcohol consumption or hereditary disorders (1). NAFLD is a complex disease with genetic and environmental modifiers; however, in its most common form, it is associated with metabolic risk factors such as obesity and diabetes (1). The clinical presentation is similar to that of alcoholic steatohepatitis (ASH), aside from the fact that a severe manifestation similar to AH does not occur in NAFLD.

ALD affects $2 \%$ to $2.5 \%$ of the general population. While the prevalence nearly doubled between 1988 to 1994 and 1999 to 2004 , overall rates have stabilized during the last decade $(8,9)$. ALD is the eighth most common cause of mortality in the United States and the second leading cause of mortality among all gastrointestinal diseases (10). Patients with ALD are at risk for AH, a severe form of ALD associated with cholestatic liver dysfunction and a poor overall prognosis (11). As the clinical symptoms of ALD may progress more rapidly than NAFLD, ALD is associated with a higher mortality rate compared with NAFLD (5-year mortality rate of $16.7 \%$ for alcoholic steatosis and more than $25 \%$ for $\mathrm{AH}$ ) (12).

Because of the increasing prevalence of obesity and the metabolic syndrome, NASH is the most common cause of chronic liver disease and is projected to become the leading etiology of end-stage liver disease requiring liver transplantation by 2020 (13). Within the last ten years, the number of patients with NAFLD 
and NASH has more than doubled. Currently, the global prevalence of NAFLD is estimated at 25\%, and it is considerably higher in obese patients and in patients with metabolic syndrome, with a prevalence of up to $65 \%-70 \%$ among type 2 diabetics $(14,15)$. Patients with NAFLD or NASH not only have a higher liver-related mortality compared with the general population, but because of comorbidities, overall and cardiovascular mortality are also increased (16-23).

Intriguingly, two totally different primary insults - ethanol in the case of ALD/ASH, and lipotoxicity and insulin resistance in the case of NAFLD/NASH - result in very similar histological presentations, which are often indistinguishable from each other. Both disease subsets manifest with macrovesicular (large droplets) steatosis, which can be centrilobular or panlobular $(24,25)$. In steatohepatitis, hepatocellular ballooning with cytoplasmic rarefication, inflammation accompanied by neutrophil and macrophage infiltration, intracytoplasmic Mallory-Denk bodies (consisting of aggregated cytoskeletal filaments), and fibrosis can be identified. ALD has a few specific histological features that appear less frequently in NAFLD/ $\mathrm{NASH}$, including typical satellitosis of neutrophils around ballooning cells and cholestasis. In addition, the overall histological appearance of NASH is usually milder than that of ASH (26). Besides similar histology and clinical presentation, NASH and ASH share further pathogenic similarities. In both diseases, a trigger injury interferes with lipid homeostasis, leading to organelle dysfunction, such as ER and mitochondrial stress, that often culminates in cell death. This stress secondarily incites inflammatory processes. Nonetheless, several disease-specific molecular distinctions have been elucidated, such as downstream TLR4 signaling (MyD88-dependence in NASH versus MyD88-independence in ASH), inflammasome and IL-1 $\beta$ signaling in ASH, lipotoxicity and insulin resistance in NASH, and differential microRNA (miR) expression, such as miR-155 upregulation in Kupffer cells, in ASH (27-33). These observations indicate that ASH and NASH are two distinct biological entities. Figures 1 and 2 summarize major pathogenic mechanisms in ALD/ASH and NAFLD/NASH, respectively.

Several therapeutic agents have been tested in NASH with variable degrees of success (34-38), and the development of new therapeutic modalities remains an area of intense ongoing clinical research. In contrast, therapies aimed at $\mathrm{ASH}$ are limited, with corticosteroids used for severe $\mathrm{AH}$, although this treatment is controversial (39). In the case of end-stage liver disease due to either disease entity, treatment options are largely supportive, with liver transplantation being the salvage treatment for end-stage liver disease. Given the singularity of the histological presentation of NASH and ASH, which result from two totally different insults with many shared pathological mechanisms, coupled with the diversity of cellular signaling implicated in disease pathogenesis, we first focus on pathogenic similarities of these diseases, followed by pathogenic distinctions that have unique therapeutic implications (Tables 1 and 2).

\section{Similar pathophysiological concepts of NASH and ASH with clinical and therapeutic implications}

Steatosis. Steatosis is a common (and usually the first) histological finding in NAFLD and ALD, induced by caloric excess in NAFLD and ethanol metabolism in ALD. In both diseases, an imbalance between hepatic lipid synthesis, lipid flux, and degradation (fatty acid oxidation [FAO]) is a critical component of the pathophysiology that involves the same master regulators and enzymatic machinery. This imbalance leads to fat accumulation within hepatocytes that results in the typical pattern of macrovesicular steatosis (40). Master regulators of steatosis and key regulatory enzymes are highly conserved. SREBP1c regulates lipogenic genes and therefore fat synthesis, while PPAR $\alpha$ and PPAR $\delta$ are crucial regulators of FAO (41). Both SREBP1c and PPARs are controlled by PPAR $\gamma$ coactivator $1 \alpha$ and $1 \beta$ (PGC1 $\alpha$ and $-\beta)$ (42). Ethanol consumption increases SREBP1c expression directly or indirectly via downregulation of factors that reduce SREBP1c, such as sirtuin 1 (SIRT1) $(43,44)$. Disruption of SREBP1c has been shown to reduce ethanol-induced fatty liver in mice (45). Caloric excess and high fat intake inactivates PGC1 $\alpha$ and stabilizes SREBP1c via SIRT1 and histone acetyltransferase. In addition, upregulation of SREBP1c has been demonstrated in NAFLD (41, 46-48).

Acetyl-CoA carboxylase (ACC) is the rate-limiting enzyme in de novo lipogenesis, while carnitine palmitoyltransferase (CPT) is the rate-limiting enzyme for mitochondrial $\beta$-oxidation, which mediates lipid degradation. Both increased ACC activity and decreased CPT activity result in fat accumulation and steatosis. Ethanol may lead to this imbalance through inhibition of AMPK, a central regulator of cell metabolism (49). Increased ACC expression has also been observed in animal models of NAFLD (50). In combination, obesity, metabolic syndrome, and high alcohol intake result in disequilibrium of these mechanisms through stimulation of de novo lipogenesis and decreased FAO, which in turn result in increased fat storage in hepatocytes. 


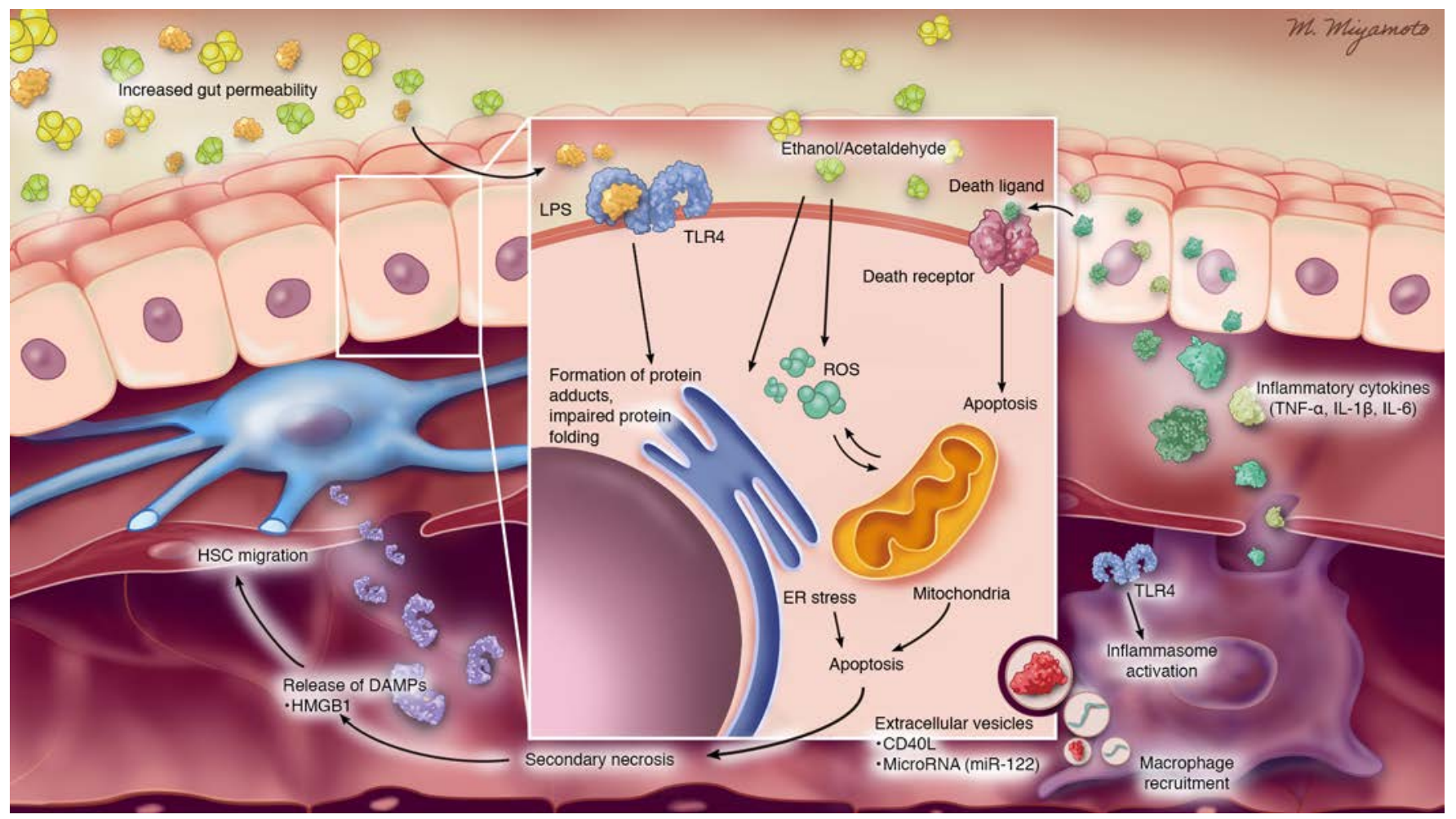

Figure 1. Pathogenic processes in alcoholic liver disease. Ethanol leads to increased gut permeability, which results in an increased release of LPS into circulation. LPS then activates TLR4 on macrophages and hepatocytes to trigger inflammatory responses. Ethanol can also directly act on hepatocytes by inducing organelle dysfunction and oxidative stress, which result in induction of proapoptotic cascades. Hepatic cells release extracellular vesicles and damage-associated molecular patterns (DAMPs) that recruit macrophages to the site of cell death, resulting in hepatic stellate cell (HSC) activation and migration. Cell death receptors that incite apoptosis can be activated by TRAIL or via proinflammatory cytokines released from macrophages. SEC, sinusoidal endothelial cell. Illustrated by Mao Miyamoto.

Several agents targeting steatosis and lipid metabolism are in early- or late-stage development. Elafibranor and GFT505 are PPAR $\alpha$ and $-\delta$ agonists that reduce steatosis, inflammation, and fibrosis (51). ACC1 may also be targeted, as treatment of rodent models with the ACC1 antagonist ND-630 exhibited reduced hepatic steatosis (52). Another target is stearoyl-CoA desaturase 1 (SCD), a rate-limiting enzyme in monounsaturated fatty acid synthesis. SCD inhibition by fatty acid/bile acid conjugates such as aramchol increases FAO and reduces lipogenesis, thereby promoting a decrease in liver fat (53); however, no positive effect on NASH has been documented. Diacylglycerol acyltransferase (DGAT) is a triglyceride synthesis-catalyzing enzyme, and DGAT inhibition decreases hepatic steatosis in animal models $(54,55)$. Further, the DGAT1 inhibitor pradigastat improved steatosis in NAFLD patients in a small randomized controlled trial (54). In summary, blocking master regulators and enzymes involved in steatosis as the first step in the pathogenesis of both NASH and ASH may disrupt a common cascade from steatosis to steatohepatitis and cirrhosis. However, steatosis need not progress to steatohepatitis, and the severity of steatosis per se does not predict NAFLD progression or liver-related mortality $(56,57)$. Moreover, whether blocking steatosis will ameliorate established steatohepatitis has not been convincingly demonstrated. In fact, ameliorating steatosis might even be harmful given several studies showing increased liver injury and fibrosis in NAFLD models $(58,59)$.

Cell death pathways. In general, cell death can be activated by cell-intrinsic pathways or via cell surface death receptors (60-63). Death receptors are members of the TNF receptor family. The cytoplasmic regions of these receptors ("death domains") trigger caspase protease activation in response to death receptor ligation and receptor clustering (64). Hepatocyte cell death due to caspase activation appears to be partially mediated by death receptors in both ASH and NASH. The importance of death receptors, particularly TRAIL receptor-2-induced (TRAIL-R2-induced) hepatocyte cell death in NASH, has been demonstrated in cell culture, animal models, and correlative human studies $(65,66)$. Moreover, toxic lipids such as free cholesterol, ceramides, and free fatty acids can activate TRAIL-R2 signaling, resulting in cell death (67, 68). TRAIL-R2 appears to be the key mediator for so-called lipoapoptosis, as the saturated free fatty acid 


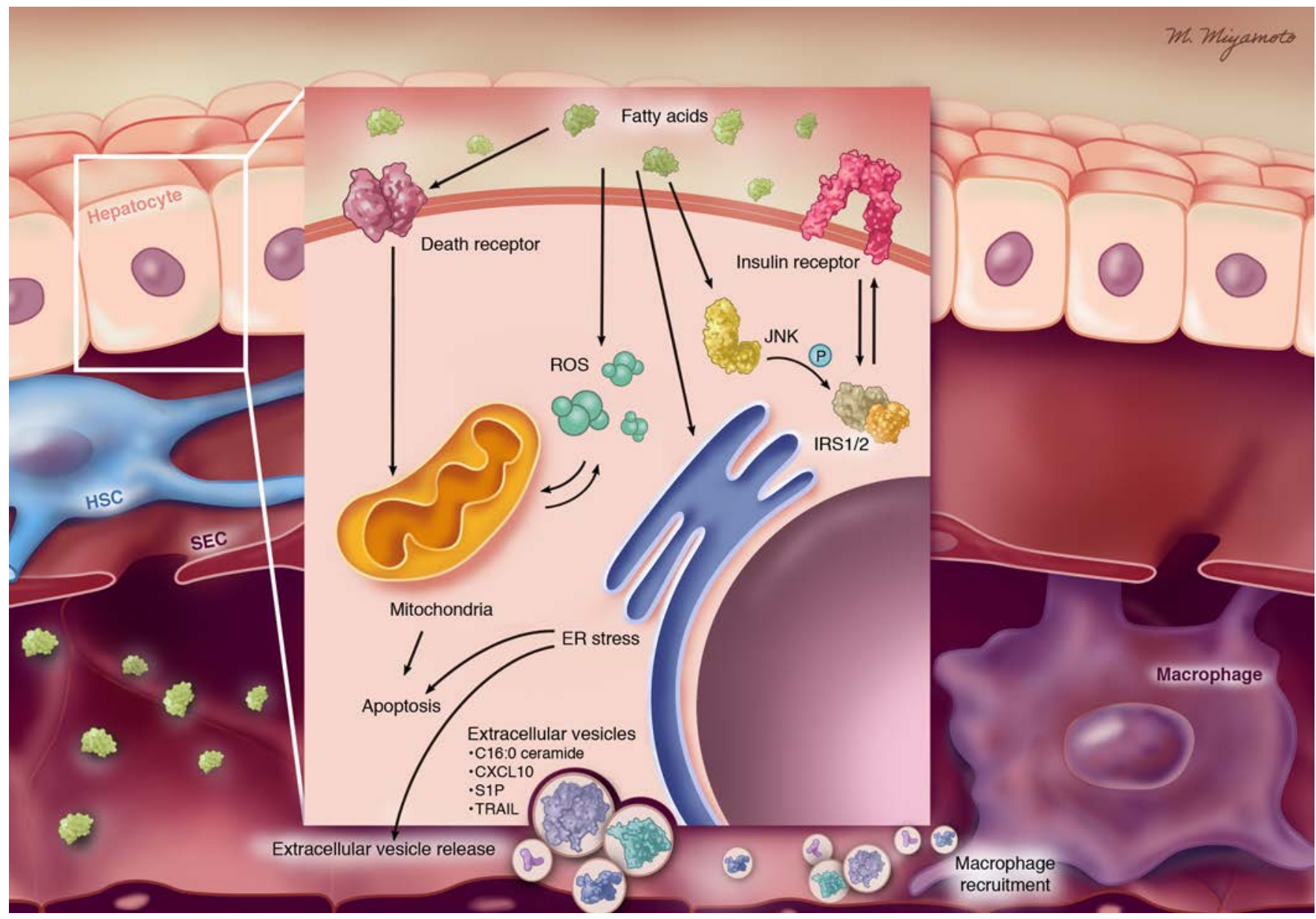

Figure 2. Pathogenic processes in nonalcoholic fatty liver disease. Free fatty acids lead to death receptor activation, which results in cell death (lipoapoptosis). In addition, fatty acids lead to organelle dysfunction and oxidative stress, which incite proapoptotic cascades. Free fatty acids may interfere with insulin signaling by blocking insulin activation of insulin receptor substrate-1 (IRS1). Inhibition of insulin sensitivity by free fatty acids requires activation of kinases such as JNK. Hepatic cells release extracellular vesicles, which then recruit macrophages to the site of liver injury. Illustrated by Mao Miyamoto.

palmitate induces ligand-independent TRAIL-R2 activation $(65,69)$. Intriguingly, targeting steatosis by SCD inhibition may lead to the same effect, resulting in increased liver injury despite a net reduction of triglyceride content (58). A role for the TRAIL pathway has also been suggested in ALD, where alcohol intake results in TRAIL-mediated steatosis (70).

Several cell-intrinsic organelle stress pathways have been implicated in NASH-associated hepatocyte cell death, including ER stress, mitochondrial dysfunction, and lysosomal permeabilization (71). Intrinsic stress pathways leading to apoptosis are mainly regulated by pro- and antiapoptotic members of the Bcl2 family. Cytotoxic stimuli such as ER stress (induced by alcohol or lipotoxicity) or ROS activate BH3 (Bcl2 homology 3) family members (initiators), while Bcl2-like proteins (guardians) are inhibited (72). This imbalance in favor of proapoptotic factors activates effector proteins that induce mitochondrial disruption and release of cytochrome $c$, which subsequently triggers effector caspase activation. Thus, caspase-dependent extrinsic and intrinsic apoptosis pathways are highly conserved and may serve as a therapeutic target in both NASH and ASH.

TNF- $\alpha$-induced hepatocyte apoptosis may be mediated through a relay kinase module consisting of apoptosis signal-regulating kinase 1 (ASK1), which in turn activates JNK. Supporting the involvement of this pathway, ASK1 deficiency attenuates high-fat diet-induced steatosis $(73,74)$. The ASK1 inhibitor GS-4997 is currently under investigation in NASH patients (ClinicalTrials.gov, NCT02466516) (75). Recent phase II data demonstrated reduction of fibrosis without worsening of steatohepatitis after only 24 weeks of GS-4997 treatment in NAFLD patients (76). Caspase- 8 and FADD-like apoptosis regulator (CFLAR) has been identified as a key suppressor of NASH that directly blocks ASK1/JNK1 activation (77). Therefore, CFLAR-mimicking drugs represent a novel therapeutic option for fatty liver disease. 
Table 1. Therapeutic opportunities based on similarities between ALD/ASH and NAFLD/NASH

\begin{tabular}{|c|c|c|c|c|}
\hline Pathomechanism & Therapeutic targets & Agents & Efficacy & Ongoing trials \\
\hline \multirow[t]{3}{*}{ Hepatosteatosis } & ACC1 & Inhibitor (ND-630) & $\begin{array}{l}\text { Reduction of steatosis in } \\
\text { rodent models }\end{array}$ & \\
\hline & Stearoyl-CoA desaturase 1 & Inhibitor (aramchol)A (53) & $\begin{array}{c}\text { Decrease in amount of fat, no } \\
\text { effect on NASH }\end{array}$ & NCT02279524 (NASH) \\
\hline & $\operatorname{PPAR} \alpha / \delta$ & Agonists (elafibranor, GFT505) & $\begin{array}{l}\text { Reduction of steatosis, } \\
\text { inflammation, and fibrosis }\end{array}$ & NCT02704403 (NASH) \\
\hline \multirow{5}{*}{$\begin{array}{l}\text { Cell death; } \\
\text { caspase activation; } \\
\text { death receptor signaling }\end{array}$} & Antioxidants & Vitamin E (tocopherol)A (35) & $\begin{array}{c}\text { Reduction of hepatosteatosis } \\
\text { and inflammation }\end{array}$ & \\
\hline & $\begin{array}{l}\text { ASK/JNK-mediated } \\
\text { cell death }\end{array}$ & $\begin{array}{l}\text { CS-4997, ASK1 inhibitors, CFLAR- } \\
\text { mimicking drugs }\end{array}$ & $\begin{array}{l}\text { Attenuation of high-fat- } \\
\text { induced steatosis }\end{array}$ & NCT02466516 (NASH) \\
\hline & Caspase-induced apoptosis & Caspase inhibitors (IDN-656) & Ameliorates NASH & NCT02686762 (NASH) \\
\hline & TNF- $\alpha$ & Anti-TNFA $(78,79)$ & $\begin{array}{l}\text { Efficacious in animal models, } \\
\text { no survival benefit in } \mathrm{AH} \text {, even } \\
\text { higher rates of infections }\end{array}$ & \\
\hline & & Pentoxifylline ${ }^{A}$ (39) & $\begin{array}{c}\text { Conflicting; maybe additional } \\
\text { to prednisone in } \mathrm{AH} \\
\text { management }\end{array}$ & \\
\hline \multirow[t]{4}{*}{ Innate immune response } & EV release & ROCK-1 inhibition, S1P inhibition & $\begin{array}{c}\text { Decreases liver injury, } \\
\text { inflammation, and fibrosis, } \\
\text { ameliorates NASH }\end{array}$ & \\
\hline & Macrophages & CCR2/5 antagonist (cenicriviroc) & $\begin{array}{c}\text { Antifibrotic effect in different } \\
\text { animal models }\end{array}$ & NCT02217475 (NASH) \\
\hline & Neutrophils & Corticosteroids ${ }^{A}$ (39) & $\begin{array}{l}\text { Trend toward reduced 28-day } \\
\text { mortality in } \mathrm{AH}\end{array}$ & \\
\hline & & $\mathrm{G}-\mathrm{CSF}^{\mathrm{A}}(219)$ & $\begin{array}{l}\text { Possibly better survival rates } \\
\text { in } \mathrm{AH}\end{array}$ & NCT01820208 (AH) \\
\hline \multirow[t]{4}{*}{ Fibrogenesis } & TGF- $\beta$ & $\begin{array}{c}\text { TGF- } \beta \text { Ab (lerdelimumab), soluble } \\
\text { TGF- } \beta 1 \text { receptor }\end{array}$ & $\begin{array}{l}\text { Attenuates fibrogenesis } \\
\text { in rodents, increased } \\
\text { inflammatory response }\end{array}$ & \\
\hline & ECM & Lysyl oxidase Ab (simtuzumab) & $\begin{array}{l}\text { Antifibrotic effect in different } \\
\text { animal models }\end{array}$ & $\begin{array}{c}\text { NCT02217475 (CCR2/5, } \\
\text { NASH) }\end{array}$ \\
\hline & Integrins & Anti-integrins & $\begin{array}{c}\alpha_{v} \text { integrin Ab with antifibrotic } \\
\text { effect in several organs } \\
\text { (animal models) }\end{array}$ & NCT01672866 (NASH) \\
\hline & $\mathrm{SHH}$ & SHH inhibition & $\begin{array}{l}\text { Improves liver inflammation } \\
\text { and fibrosis }\end{array}$ & \\
\hline
\end{tabular}

Further, inhibitors of caspase activation may serve as therapeutic targets, and caspase inhibitors such as emricasan are currently being investigated in NASH patients (NCT02686762). In ASH, however, a trial evaluating emricasan had to be terminated because of pharmacokinetic issues (NCT01912404). Although TNF- $\alpha$ seems to be a key player in liver inflammation and animal models, suggesting that TNF-targeted antibodies could potentially be used to reduce liver injury and even portal hypertension, trials with a TNF-blocking antibody and a soluble TNF receptor showed disappointing results, with no survival benefit and increased rates of infectious complications in comparison with placebo in $\mathrm{AH}$ (78, 79). These negative results may be due to the blockage of the pleiotropic effects of TNF- $\alpha$ and TNF-related proinflammatory cytokines, which promote liver regeneration (80).

Necroptosis is a nonapoptotic cell death pathway that is initiated by cell surface death receptor activation with engagement of receptor interaction protein kinase-1 (RIPK1) and RIPK3 and the pseudokinase mixed-lineage kinase domain-like (MLKL) (81). Necroptosis has been examined in experimental models of ALD and NAFLD with observation of opposing effects (82-84). Ethanol-induced hepatocyte injury has been reported to be RIPK3-dependent, but independent of RIPK1 activity (85). In contrast, necroptosis data in NASH are very limited and inconsistent. While Gautheron and colleagues showed that RIPK3 mediated liver injury, inflammation, and liver fibrosis through a pathway suppressed by caspase- 8 , data from Hatting and colleagues showed that caspase- 8 deletion was protec- 
Table 2. Therapeutic opportunities based on differences between ALD/ASH and NAFLD/NASH

\begin{tabular}{|c|c|c|c|c|}
\hline Pathomechanism & Therapeutic strategies & Agents & Efficacy & Ongoing trials \\
\hline \multirow[t]{3}{*}{ Microbiome } & Pre- and probiotics & $\begin{array}{l}\text { VSL+3, MIYAIRI588, } \\
\text { Bifidobacterium bifidum or } \\
\text { Lactobacillus plantarum }{ }^{A} \\
(143,146,147)\end{array}$ & $\begin{array}{l}\text { Reduction of liver injury and } \\
\text { inflammation, reduction of NASH, } \\
\text { improvement of alcohol-induced } \\
\text { liver injury }\end{array}$ & $\begin{array}{l}\text { NCT02764047 } \\
\text {, (NAFLD) }\end{array}$ \\
\hline & Antibiotics & $\begin{array}{l}\text { Rifaximin, amoxicillin- } \\
\text { clavulanic acid, ciprofloxacin }\end{array}$ & $\begin{array}{l}\text { Decreases intestinal bacteria } \\
\text { growth, resulting in decrease in } \\
\text { endotoxin levels in the blood }\end{array}$ & NCT02281929 (AH) \\
\hline & Fecal transplantation & $\begin{array}{l}\text { Healthy donor fecal } \\
\text { transplantation }{ }^{A}(149)\end{array}$ & $\begin{array}{l}\text { Increased 1-year survival rate in } \\
\mathrm{AH} \text { patients }\end{array}$ & \\
\hline \multirow[t]{2}{*}{ Fatty acids and lipotoxicity } & Weight loss & Lifestyle modifications $^{A}(220)$ & $\begin{array}{l}\text { Reduction of insulin resistance; } \\
\text { efficacy depends on level of } \\
\text { weight loss }\end{array}$ & \\
\hline & FGF21 & Antagonism (BMS-986036) & Attenuates hepatic steatosis & $\begin{array}{l}\text { NCT02413372 } \\
\text { (NASH) }\end{array}$ \\
\hline \multirow[t]{4}{*}{ Insulin resistance } & Insulin resistance & Pioglitazone $^{A}$ (35) & $\begin{array}{l}\text { Insulin sensitizer, reduction of } \\
\text { steatosis, inflammation, and } \\
\text { fibrosis }\end{array}$ & \\
\hline & & GLP1 agonist ${ }^{\mathrm{A}}$ (34) & $\begin{array}{l}\text { Insulin sensitizer, promotes } \\
\text { satiation and weight loss }\end{array}$ & $\begin{array}{l}\text { NCT02654665 } \\
\text { (NASH) }\end{array}$ \\
\hline & & DPP-4 antagonist & $\begin{array}{l}\text { Reduction of steatosis in animal } \\
\text { models }\end{array}$ & $\begin{array}{l}\text { NCT01963845 } \\
\text { (NAFLD) }\end{array}$ \\
\hline & & Metformin ${ }^{A}(183)$ & $\begin{array}{l}\text { Insulin sensitizer; meta-analysis } \\
\text { did not show efficacy in NASH } \\
\text { treatment }\end{array}$ & \\
\hline Inflammasomes & Inflammasomes & IL-1 blockage (anakinra) & $\begin{array}{l}\text { Attenuates alcohol-induced liver } \\
\text { inflammation, steatosis, and } \\
\text { damage }\end{array}$ & NCT01809132 (AH) \\
\hline MicroRNA & miR-155 & Silencing via antagomirs & & \\
\hline
\end{tabular}

tive $(86,87)$. The fact that liver-specific caspase- 8 knockout led to increased RIPK3 expression even in the controls (without methacholine-deficient diet) may be an important limitation in the study of Gautheron et al. (88). Notably, the expression of RIPK3 in hepatocytes is quite controversial, and the role of RIPKs in ASH and NASH remains unclear (88).

Autophagy is important for different cellular mechanisms, including survival of the cells by self-digestion and elimination of potentially harmful proteins and organelles, while dysregulation and decreased function of autophagic processes have been suggested in both ALD and NAFLD pathogenesis (89). In contrast, intact autophagy seems to attenuate alcohol-induced injury and lipotoxicity (89).

Although oxidative stress has been implicated in the pathogenesis of NASH and ASH, studies investigating the therapeutic potential of antioxidants have been disappointing $(90,91)$, with the exception of the vitamin $\mathrm{E}$ isoform tocopherol, which is considered a potential treatment in nondiabetic, noncirrhotic NASH patients based on the phase III, multicenter, randomized controlled Pioglitazone, Vitamin E, or 
Placebo for NASH (PIVENS) trial (36). Nonetheless, vitamin E is used infrequently in clinical practice because of concerns regarding its long-term safety profile, as it has been shown to potentially increase overall mortality and risk of prostate cancer $(92,93)$.

Innate immune responses. Innate immune cells play a crucial role in both ASH and NASH, although the specific subsets of cells involved are slightly different in each disease. Hepatic resident macrophages, known as Kupffer cells, and macrophages derived from recruited myeloid cells are implicated in both NASH and ASH $(94,95)$. Injured hepatocytes release endogenous alarmins known as damage-associated molecular patterns (DAMPs). DAMPS activate conserved pattern recognition receptors on innate immune cells, especially macrophages. The DAMP high-mobility group protein box 1 (HMGB1) has been shown to activate TLR4 in ASH and NASH $(96,97)$, although Schwabe and colleagues recently questioned the role of HGMB-1 in liver pathogenesis (98). However, in NAFLD-related hepatocyte damage other DAMPs such as sonic hedgehog (SHH) ligand have been linked to disease progression (99). In addition to DAMPs, damaged cells release both soluble and extracellular vesicle-contained (EV-contained) proinflammatory signals. In NASH, EV cargoes include the proinflammatory chemokine CXCL10, which recruits macrophages, and TRAIL, which activates macrophages through death receptor signaling and leads to increases in IL-1 $\beta$ and IL-6 (65, 100, 101). In ALD, CD40 ligand-containing (CD40L-containing) EVs are released by hepatocytes and, in turn, activate CD40 on macrophages, which induces proinflammatory signaling (102). Sphingolipid cargoes, specifically C16:0 ceramide and sphingosine 1-phosphate (S1P), on EVs are implicated in the recruitment of macrophages to the steatotic liver in NASH (103). Macrophages themselves communicate through EVs, and EV-trafficked miRs such as miR-27a enable communication between alcohol-exposed monocytes and naive monocytes, which further promotes sterile inflammation (104). Thus, inhibition of EV release and interruption of signaling pathways activated by EV cargoes represent attractive therapeutic targets. Preclinical studies demonstrate the utility of both paradigms. Inhibition of Rho-associated coiled-coil-containing protein kinase 1 (ROCK-1), which mediates EV release in lipotoxic hepatocytes, reduced serum EV levels and decreased liver injury, inflammation, and fibrosis in mice with NASH (105). In addition, inhibition of EV-associated S1P signaling with the S1P1 receptor antagonist FTY720 ameliorated murine NASH (106).

Neutrophils are another key element in ASH, and they promote ALD progression by inducing hepatocyte injury via release of ROS, proteases, and proinflammatory mediators (107). Intriguingly, neutrophilic infiltration is associated with a better outcome in AH (108), as neutrophils may secrete cytokines that stimulate liver regeneration (109). Thus, the biology of neutrophils in ASH is complex. Given the positive effect of functionally intact neutrophils (108), a large trial investigating granulocyte-CSF (G-CSF) in difficult-to-treat AH is currently under way (NCT01820208) (75). The exact mechanisms governing how neutrophils affect NAFLD/NASH remain elusive. Neutrophil elastase (NE) causes cellular insulin resistance, and its deletion improves insulin resistance and tissue inflammation (110), suggesting that NE may be a therapeutic target.

Macrophages are the other key proinflammatory cell type in NASH and ASH. Interruption of signaling pathways leading to macrophage recruitment and/or activation represents a promising therapeutic approach. Monocyte chemoattractant protein-1 (MCP-1), which is released by Kupffer cells and hepatocytes in response to chronic ethanol consumption, recruits macrophages to the site of tissue injury (111). Other key cells in liver pathology such as sinusoidal endothelial cells and hepatic stellate cells also produce elevated MCP-1 levels, therefore contributing to and maintaining mononuclear cell infiltration $(112,113)$. MCP-1 has been shown to be involved in both ASH and NASH pathogenesis $(111,114)$. MCP-1 acts via its receptors CCR2 and CCR5, and loss of CCR2 has been demonstrated to inhibit the development of steatohepatitis, fibrosis, and insulin resistance (114). The CCR2/5 inhibitor cenicriviroc prevents monocyte/macrophage recruitment and hepatic stellate cell activation, resulting in an antifibrotic effect (114-116). A phase IIb trial of cenicriviroc in NASH patients is currently ongoing (NCT02217475) (117). An intermediate analysis of the ongoing 2-year trial demonstrated significantly better outcome regarding reduction in fibrosis ( $\geq 1$ stage) in patients treated with cenicriviroc compared with placebo, although the primary outcome was not met (an improvement of at least 2 points) (118).

Fibrogenesis. Hepatic stellate cells are the key players in liver fibrogenesis in both NAFLD and ALD. General antifibrotic therapies in liver diseases have been reviewed elsewhere in more detail (119). Targeting early steps in liver injury or inflammation, such as the MCP1/CCR2 or HMGB1/TLR4 interactions, may attenuate fibrogenesis, as those mechanisms may ultimately lead to hepatic stellate cell activation. Here, we focus on fibrogenic mechanisms that may be targeted directly in ASH and NASH management. 
Given its key function in fibrosis development, TGF- $\beta$ signaling has been a primary therapeutic target that can be modulated directly with antibodies such as lerdelimumab, soluble TGF- $\beta 1$ receptors, or small molecules that attenuate TGF- $\beta$ downstream signaling (120-124). However, systemic TGF- $\beta$ inhibition increased inflammatory responses, so simple blockade of these key elements might not be effective because of the complexity of fibrogenesis $(119,125)$. More specific and localized targeting of TGF- $\beta$ activation might demonstrate higher efficacy, such as blocking the TGF- $\beta$ downstream mediator connective tissue growth factor (CTGF) through the monoclonal antibody FG-3019 (NCT01217632). This study evaluating FG-3019 (as an add-on to entecavir) in subjects with liver fibrosis due to chronic hepatitis B infection has, however, been recently terminated because of an unexpected prominent effect of the antiviral agent alone. As interactions between the extracellular matrix (ECM) and cells are now considered to be critical to the development of fibrosis, both ECM proteins and integrins, which mediate the interaction between ECM and hepatic cell populations, have become targets of interest. Inhibition of integrins attenuates fibrogenesis (126). Simtuzumab, an antibody against the collagen cross-linking enzyme lysyl oxidase, is currently under investigation in NASH patients (NCT01672866) (127). However, as recently presented, there was no additional benefit from simtuzumab in NASH patients treated with an ASK1 inhibitor (76). While the mechanisms described above are highly conserved and may be targeted in both ASH and NASH, other factors are more specific, such as SHH in NASH. SHH is believed to be a key player in the wound-healing response (128). In response to lipotoxicity, ballooned hepatocytes release $\mathrm{SHH}$ (99), which induces expression of TGF- $\beta$ in hepatic stellate cells $(129,130)$. SHH inhibitors such as cyclopamine and vismodegib have been studied in vitro and in animal models of NASH (128). Given the complexity of fibrogenesis and the multiple pathways that are involved in the process, combination therapies targeting two or more modes of action may lead to better, synergistic results (119) and fewer side effects.

\section{Different underlying pathophysiologies and therapeutic implications}

The microbiome and LPS signaling. The human microbiome is extremely diverse, and the quantity of intestinal bacteria is immense, with an estimated 10 trillion to 100 trillion microbes per gram of stool, including 500 to 1,000 highly prevalent species (131). Although dysbiosis of the intestinal microbiome has been reported in both ALD and NAFLD, the microbiome alterations associated with each disease are distinct (132). Very recently, chronic alcohol consumption has even been linked to an altered mycobiota and translocation of fungal products (133). The interplay between gut, microbiome, and liver disease is complex and only partially understood. A comparison of stool samples is difficult given numerous external factors influencing each individual's microbiome. In ALD, the composition of intestinal microbiota depends on the fibrotic/cirrhotic stage of the disease and on alcohol intake (chronic versus binge versus social drinker) (134-136). Alcohol consumption increases gut permeability via breakdown of alcohol into acetaldehyde $(135,137)$. Increased gut permeability results in increased transmigration of bacterial DNA and endotoxins (LPS) from Gram-negative bacteria into portal circulation, which can activate Kupffer cells through activation of TLRs (mainly TLR4 and TLR9) $(138,139)$. Activated Kupffer cells produce different inflammatory cytokines. The same events may occur in NAFLD, as predisposition to NAFLD is associated with increased expression of TLR4 and TLR9 in the liver. Further, the microbiome is also significantly altered in NASH (with increases in Prevotella and Porphyromonas species and decreased Bacteroidetes species) (140). Therefore, gut microbiota may control the severity of NAFLD via a comparable axis. However, TLR4 shows a unique ability to activate two distinct pathways. One pathway is MyD88-dependent and leads to activation of NF- $\mathrm{BB}$ and proinflammatory cytokines, while the other pathway is MyD88-independent and leads to induction of type I IFNs and $\mathrm{NF}-\kappa \mathrm{B}$ (141). Intriguingly, studies suggest a differential contribution of MyD88-dependent and -independent pathways in ASH and NASH pathogenesis, respectively, as there appears to be a crucial role for MyD88-dependent signaling in NASH, but not in ASH (27-29). The reasons for the differences in TLR4 downstream signaling remain elusive; however, adipocytokines released under conditions of energy surplus may be causative factors, as they have been demonstrated to inhibit MyD88-dependent pathways in macrophages (142).

As the exact role of the microbiome in the pathophysiology of NAFLD and ALD remains elusive, it is presently difficult to predict how alteration of the microbiota will affect the liver. Several proand prebiotics, such as VSL+3, MIYAIRI588, Bifidobacterium bifidum, and Lactobacillus plantarum, and antibiotics may have beneficial effects (143-147). Nonetheless, conflicting data on VSL +3 suggesting a detrimental effect on hepatic steatosis raise questions about interindividual differences in response to probiotics (148). Despite some evidence in other gastrointestinal and nongastrointestinal diseases, 
modulation of gut microbiota by fecal transplantation has not been studied in liver disease so far except for a very recent pilot study in AH showing that transplantation was associated with increased 1-year survival rates (149). Restraining LPS signaling through LPS antibodies and blocking the TLR4/ LPS interaction may be promising treatment options and are currently under investigation (IMM124E for severe AH, NCT01968382; and JKB121 for NASH, NCT02442687).

Fatty acids and lipotoxicity. Although altered lipid metabolism plays an important role in ALD, accumulation of fatty acids and lipotoxicity is best studied in NAFLD pathophysiology. Energy surplus leads to an increase in adipocytokines, which in turn prevent adipocytes from assimilating fatty acids and, along with insulin resistance, promote the release of excess fatty acids from adipose tissue into the circulation. The liver is then inundated by fatty acids, where their uptake contributes to lipotoxicity $(150,151)$. Lipotoxicity occurs through different mechanisms: (a) direct cytotoxicity via perturbed FAO and generation of ROS, which interferes with mitochondrial respiration, leading to a more vulnerable organelle and probably the release of factors that promote apoptosis and induction of other cell death cascades (152-156); (b) increased insulin resistance and hyperinsulinemia via fatty acid accumulation (157); (c) changes in cell signaling via hepatic nuclear factor- $\alpha(\mathrm{HNF} \alpha)$ or TLRs $(158,159)$; (d) ER stress and upregulation of autophagic processes (lipoapoptosis) $(160,161)$; and (e) macrophage recruitment, which is, in part, mediated through proinflammatory cargo on EVs such as CXCL10, TRAIL, and S1P (103). In contrast to NASH, the role of free fatty acids and lipotoxicity in ASH pathogenesis has not yet been defined, although the accumulation of free fatty acids has been documented in ALD (162).

Energy surplus with consequent lipotoxicity can be addressed by lifestyle modifications, weight loss, or bariatric surgery (an option only in those patients with morbid obesity owing to postoperative morbidity). The study by Lassailly and colleagues provided strong evidence that bariatric surgery ameliorates NASH (in $85 \%$ of patients within the first year) and reduces fibrosis (in $30 \%$ of patients) (163). The effects of lipotoxicity may be targeted through different aforementioned approaches such as antioxidants, insulin sensitizers, TLR antagonists, or antiapoptotic agents. FGF21 is a regulator of lipid metabolism and reduces hepatic lipid accumulation in an insulin-independent manner (164-166). Furthermore, FGF21 leads to a decrease in free fatty acids by inhibiting lipolysis in adipose tissue (167). FGF21 has been reported to attenuate hepatic steatosis in animal models and therefore may serve as a novel therapeutic approach (168-172); pegylated FGF21 (BMS-986036) is currently under investigation in NASH patients (NCT02413372).

Insulin resistance. Both obesity and NAFLD are strongly associated with hyperinsulinemia and insulin resistance (173). Insulin is a crucial lipid-regulating factor, and insulin resistance leads to increased lipolysis in adipose tissue and therefore increased delivery of fatty acids into the liver. As hepatocytes retain sensitivity to insulin-induced lipogenesis, hyperinsulinemia further promotes steatosis (174). Furthermore, molecular pathways linking inflammation and insulin resistance have been elucidated. Proinflammatory cytokines (e.g., TNF- $\alpha$ ) can induce insulin resistance $(175,176)$, and cellular stress such as ROS and ER stress can lead to insulin resistance through activation of $\mathrm{JNK}$ and NF- $\mathrm{kB}$, two canonical pathways in the pathogenesis of obesity-induced insulin resistance. However, lipid accumulation is insufficient to cause insulin resistance (177). Steatosis can occur independently of insulin resistance, and the presence of obesity and/or metabolic syndrome is not a sine qua non for insulin resistance. The exact role of the insulin signaling pathway in ASH has yet to be defined, although insulin resistance may result from alcohol's effect on hepatic and nonhepatic tissue (178). In adipose tissue, chronic alcohol consumption leads to an increase in lipolysis through an impaired insulin-mediated suppression of lipolysis (179), and rosiglitazone, an insulin sensitizer, has been shown to reduce ethanol-induced adipose dysfunction in mice (180).

Due to its key role in NASH pathogenesis, therapeutic strategies that focus on insulin resistance with insulin sensitizers such as rosiglitazone and pioglitazone or GLP1 agonists such as liraglutide are promising treatment options (34). Liraglutide not only reduces insulin resistance but, in contrast to pioglitazone, also promotes satiation and weight loss. Randomized controlled trials have provided evidence for the efficacy of rosiglitazone and pioglitazone, and pioglitazone is currently listed as a potential treatment for NASH in the American Association for the Study of Liver Diseases guidelines $(35,36,181)$. In a proof-of-concept study with 55 NASH patients, 6 months of treatment with pioglitazone led to significant metabolic and histological improvement; indeed, necroinflammation was reduced in $85 \%$ compared with a placebo rate of $38 \%$ (number needed to treat, 2.1) (35). Nonetheless, there are concerns regarding its safety profile ( 35 , $36,182)$. Other insulin sensitizers such as metformin have failed to effectively reduce NASH (183). There are no data to support the use of insulin sensitizers in humans with ASH. 
Nuclear receptors. Nuclear receptors are ligand-activated transcription factors and play an important pathophysiological role in NAFLD/NASH (184). They act as intracellular sensors for free fatty acids and cholesterol metabolism and are major regulators of cell metabolism as well as cell differentiation and cellular homeostasis $(185,186)$. PPAR $\alpha$ promotes fatty acid mitochondrial $\beta$-oxidation, thereby decreasing steatosis (187-189). Farnesoid X receptor (FXR) acts as a sensor for bile acids and inhibits bile acid synthesis if the bile acid pool is increased, thereby protecting hepatocytes from the toxic effect of bile acids (190). FXR also has many other functions, such as antiinflammatory effects, promotion of FAO through upregulation of PPAR $\alpha$, and decreasing of fat synthesis through downregulation of SREBP1. FXR also has a beneficial role in glucose metabolism and is important in vascular remodeling (191-193). In addition, FXR increases FGF19 secretion in enterocytes, which in turn results in energy expenditure and fat oxidation; this FXR/FGF19 gut-liver axis is involved in liver growth and regeneration $(194,195)$. In NAFLD patients with insulin resistance, the hepatic response to FGF19 is markedly impaired (196).

PPAR subtypes as well as FXR serve as potential therapeutic targets in NAFLD/NASH. The effects of the PPAR $\alpha / \delta$ agonist elafibranor on steatosis, inflammation, and fibrosis are described above, and PPAR $\gamma$ agonists have been discussed in more detail in the section on insulin resistance. FXR is targeted by obeticholic acid, which reduces histological features of NASH by decreasing lipogenesis and hepatic gluconeogenesis and by increasing insulin sensitivity and VLDL clearance $(37,38)$. The FXR agonist PX101, which acts as an insulin sensitizer, is currently under investigation in clinical trials (NCT01998659). The role of FXR and the PPARs in ASH has yet to be determined. There is currently a trial of obeticholic acid under way in patients with moderately severe AH (NCT02039219).

Inflammasomes. Inflammasomes are multiprotein complexes expressed in myeloid cells involved in innate inflammation (197). Inflammasomes sense proinflammatory signals through NOD-like receptors (NLRs), which incite mediator proteins such as the adaptor protein apoptosis-associated speck-like protein (ASC) and secondarily trigger its effector protein, caspase-1 (197-201). Caspase-1 cleaves pro-IL-1 $\beta$, pro-IL-18, and pro$\mathrm{IL}-23$, resulting in sterile inflammation. Inflammasomes are expressed mainly in inflammatory cells, but also in hepatocytes to a smaller extent (197). In animal models of chronic alcohol consumption, inflammasome components, including NLRP1, NLRP3, ASC, caspase-1, and pro-IL-1 $\beta$, are upregulated (31, 202, 203). Moreover, mice deficient in ASC, caspase-1, and IL-1 receptor are protected from ethanol-induced liver injury, inflammation, and steatosis (31). In NASH models, mRNAs encoding members of the inflammasome complex were also elevated (204). There are several differences in inflammasome activation in ASH and NASH: (a) Inflammasomes and IL-1 secretion are induced at very early stages in ASH, while IL-1 and caspase-1 (a surrogate marker for inflammasome activity) are not activated in early NASH (31-33). (b) Inflammasome deficiency consistently protects against liver steatosis only in NASH models, while the absence of IL-1 signaling improves inflammation, steatosis, and liver injury in $\operatorname{ASH}(27,33,205)$. (c) Inflammasome activation typically occurs in Kupffer cells in ASH, while it is observed in hepatocytes in NASH $(31,32,141)$. Early involvement of the inflammasome in ASH pathogenesis suggests a potential therapeutic strategy of blocking IL-1 in ASH. The IL-1-blocking antibody anakinra is currently under investigation in ASH patients (NCT01809132).

MicroRNAs. MicroRNAs (miRs) are short noncoding RNAs that modulate target gene expression. Aberrant expression of miRs is associated with and may contribute to both ALD and NAFLD. Several miRs seem to be involved in lipid and/or glucose metabolism: miR-34a, which is upregulated in NASH, let7d, a miR precursor, which is downregulated in NASH, and miR-217, which is increased in ASH, all lead to a decrease in FAO through SIRT1 inhibition, thereby promoting fat synthesis (41, 206-208). Other miRs may trigger fibrogenesis in the context of alcohol consumption (miR-132). In NAFLD, miR-122 has been linked to both steatosis and fibrosis, and has been proposed as a predictive marker (209). Further up- or downregulation of other miRs may be associated with advanced fibrosis or hepatocellular carcinoma (210-212). A comprehensive review of the role of miRs in ALD has been recently published (213). MiR-155 has been linked to ethanol-induced inflammation; in particular, it is upregulated in Kupffer cells after alcohol feeding and leads to their activation and sensitization to LPS (30). The proinflammatory cytokine TNF- $\alpha$ has been identified as a major target of miR-155 (30). Although miR-155 is also induced in mouse models of NASH, its role in Kupffer cells in this setting has not yet been determined $(214,215)$. MiR-155 may serve as an interesting therapeutic target to attenuate TNF production in ASH. In general, miR manipulation (silencing via antagomirs or increasing of expression via precursors) is aimed at correcting the miR imbalance described above. The efficacy of miR-based therapeutics has been demonstrated in humans in hepatitis C virus infection and in animal models of ALD and NASH $(30,216,217)$. Given the lack of tissue- and cell-specificity, targeting miRs remains a challenge (218). 


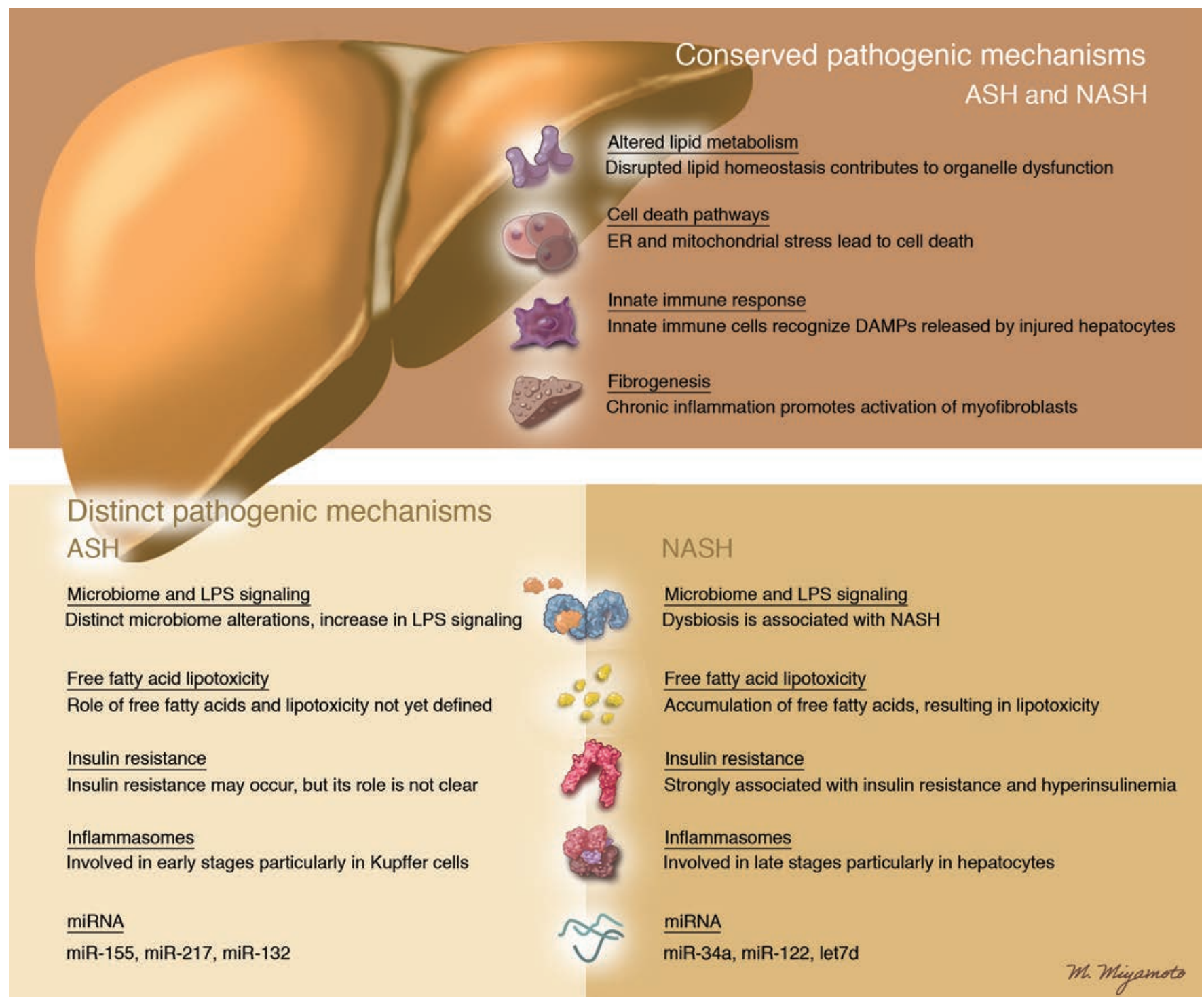

Figure 3. Overview of pathogenic similarities and differences between ASH and NASH. Illustrated by Mao Miyamoto.

\section{Summary}

ALD/ASH and NAFLD/NASH share many similarities, such as histopathological characteristics, hepatotoxicity via oxidative and ER stress, and the pivotal role of the innate immune system in all of these disease states. However, several disease-specific mechanisms, such as TLR4 downstream signaling and inflammasome component activation or lipotoxicity, demonstrate that ALD/ASH and NAFLD/NASH represent two different conditions with different therapeutic opportunities (Figure 3). Furthermore, given the multifactorial pathophysiology underlying both diseases, it is very likely that no one therapy will be efficacious, and it may be necessary to employ a combinatorial approach with agents that target different signaling components, e.g., a combination of a caspase inhibitor with a CCR2/5 inhibitor. Lastly, there is an ongoing surge in NASH clinical trials; however, ALD is underrepresented and presents an area for active discovery of potential therapeutic targets.

\section{Author contributions}

TG, HM, GJG, and VHS contributed to the writing of this Review.

\section{Acknowledgments}

This work is supported in part by Swiss National Science Foundation grant P2ZHP3_168561 to TG and by NIH grants DK107402 and DK111378 to HM, DK41876 to GJG, and AA21788 to VHS; and by Gilead Sciences and the Palumbo Foundation (to HM). 
Address correspondence to: Vijay H. Shah, Division of Gastroenterology and Hepatology, Mayo Clinic, 200 First Street SW, Rochester, Minnesota 55905, USA. Phone: 507.255.6028; E-mail: shah.vijay@mayo. edu.

1. Chalasani N, et al. The diagnosis and management of non-alcoholic fatty liver disease: practice guideline by the American Gastroenterological Association, American Association for the Study of Liver Diseases, and American College of Gastroenterology. Gastroenterology. 2012;142(7):1592-1609.

2. O'Shea RS, Dasarathy S, McCullough AJ, Practice Guideline Committee of the American Association for the Study of Liver Diseases, Practice Parameters Committee of the American College of Gastroenterology. Alcoholic liver disease. Hepatology. 2010;51(1):307-328

3. Thun MJ, et al. Alcohol consumption and mortality among middle-aged and elderly U.S. adults. $N$ Engl J Med. 1997;337(24):1705-1714.

4. Becker $\mathrm{U}$, et al. Prediction of risk of liver disease by alcohol intake, sex, and age: a prospective population study. Hepatology. 1996;23(5):1025-1029.

5. Fuchs CS, et al. Alcohol consumption and mortality among women. N Engl J Med. 1995;332(19):1245-1250.

6. Grant BF, Dufour MC, Harford TC. Epidemiology of alcoholic liver disease. Semin Liver Dis. 1988;8(1):12-25

7. Ludwig J, Viggiano TR, McGill DB, Oh BJ. Nonalcoholic steatohepatitis: Mayo Clinic experiences with a hitherto unnamed disease. Mayo Clin Proc. 1980;55(7):434-438.

8. Younossi ZM, et al. Changes in the prevalence of the most common causes of chronic liver diseases in the United States from 1988 to 2008. Clin Gastroenterol Hepatol. 2011;9(6):524-530.e1; quiz e60.

9. Younossi Z, Henry L. Contribution of Alcoholic and Nonalcoholic Fatty Liver Disease to the Burden of Liver-Related Morbidity and Mortality. Gastroenterology. 2016;150(8):1778-1785.

10. Im GY, Lucey MR. Practical concerns and controversies in the management of alcoholic hepatitis. Gastroenterol Hepatol ( $N$ Y). 2016;12(8):478-489.

11. Chedid A, Mendenhall CL, Gartside P, French SW, Chen T, Rabin L. Prognostic factors in alcoholic liver disease. VA Cooperative Study Group. Am J Gastroenterol. 1991;86(2):210-216.

12. Deleuran T, Grønbaek H, Vilstrup H, Jepsen P. Cirrhosis and mortality risks of biopsy-verified alcoholic pure steatosis and steatohepatitis: a nationwide registry-based study. Aliment Pharmacol Ther. 2012;35(11):1336-1342.

13. Charlton MR, Burns JM, Pedersen RA, Watt KD, Heimbach JK, Dierkhising RA. Frequency and outcomes of liver transplantation for nonalcoholic steatohepatitis in the United States. Gastroenterology. 2011;141(4):1249-1253.

14. Lazo M, et al. Prevalence of nonalcoholic fatty liver disease in the United States: the Third National Health and Nutrition Examination Survey, 1988-1994. Am J Epidemiol. 2013;178(1):38-45.

15. Doycheva I, et al. Non-invasive screening of diabetics in primary care for NAFLD and advanced fibrosis by MRI and MRE. Aliment Pharmacol Ther. 2016;43(1):83-95.

16. Haflidadottir S, et al. Long-term follow-up and liver-related death rate in patients with non-alcoholic and alcoholic related fatty liver disease. BMC Gastroenterol. 2014;14:166.

17. Long MT, Fox CS. The Framingham Heart Study - 67 years of discovery in metabolic disease. Nat Rev Endocrinol. 2016;12(3):177-183

18. Otgonsuren M, Stepanova M, Gerber L, Younossi ZM. Anthropometric and clinical factors associated with mortality in subjects with nonalcoholic fatty liver disease. Dig Dis Sci. 2013;58(4):1132-1140.

19. Ong JP, Pitts A, Younossi ZM. Increased overall mortality and liver-related mortality in non-alcoholic fatty liver disease. J Hepatol. 2008;49(4):608-612.

20. Ekstedt M, et al. Long-term follow-up of patients with NAFLD and elevated liver enzymes. Hepatology. 2006;44(4):865-873

21. Rafiq N, et al. Long-term follow-up of patients with nonalcoholic fatty liver. Clin Gastroenterol Hepatol. 2009;7(2):234-238.

22. Stepanova M, et al. Predictors of all-cause mortality and liver-related mortality in patients with non-alcoholic fatty liver disease (NAFLD). Dig Dis Sci. 2013;58(10):3017-3023.

23. Adams LA, et al. Nonalcoholic fatty liver disease increases risk of death among patients with diabetes: a community-based cohort study. Am J Gastroenterol. 2010;105(7):1567-1573.

24. Kleiner DE, Brunt EM. Nonalcoholic fatty liver disease: pathologic patterns and biopsy evaluation in clinical research. Semin Liver Dis. 2012;32(1):3-13.

25. Lefkowitch JH. Morphology of alcoholic liver disease. Clin Liver Dis. 2005;9(1):37-53.

26. Tiniakos DG. Nonalcoholic fatty liver disease/nonalcoholic steatohepatitis: histological diagnostic criteria and scoring systems. Eur J Gastroenterol Hepatol. 2010;22(6):643-650.

27. Miura K, et al. Toll-like receptor 9 promotes steatohepatitis by induction of interleukin-1 $\beta$ in mice. Gastroenterology. 2010;139(1):323-34.e7.

28. Petrasek J, Dolganiuc A, Csak T, Kurt-Jones EA, Szabo G. Type I interferons protect from Toll-like receptor 9-associated liver injury and regulate IL-1 receptor antagonist in mice. Gastroenterology. 2011;140(2):697-708.e4.

29. Zhao XJ, et al. TRIF and IRF-3 binding to the TNF promoter results in macrophage TNF dysregulation and steatosis induced by chronic ethanol. J Immunol. 2008;181(5):3049-3056.

30. Bala S, et al. Up-regulation of microRNA-155 in macrophages contributes to increased tumor necrosis factor \{alpha\} (TNF $\alpha$ ) production via increased mRNA half-life in alcoholic liver disease. J Biol Chem. 2011;286(2):1436-1444.

31. Petrasek J, et al. IL-1 receptor antagonist ameliorates inflammasome-dependent alcoholic steatohepatitis in mice. J Clin Invest. 2012;122(10):3476-3489.

32. Csak T, Ganz M, Pespisa J, Kodys K, Dolganiuc A, Szabo G. Fatty acid and endotoxin activate inflammasomes in mouse 
hepatocytes that release danger signals to stimulate immune cells. Hepatology. 2011;54(1):133-144.

33. Dixon LJ, Berk M, Thapaliya S, Papouchado BG, Feldstein AE. Caspase-1-mediated regulation of fibrogenesis in diet-induced steatohepatitis. Lab Invest. 2012;92(5):713-723.

34. Armstrong MJ, et al. Liraglutide safety and efficacy in patients with non-alcoholic steatohepatitis (LEAN): a multicentre, double-blind, randomised, placebo-controlled phase 2 study. Lancet. 2016;387(10019):679-690.

35. Belfort R, et al. A placebo-controlled trial of pioglitazone in subjects with nonalcoholic steatohepatitis. $N$ Engl J Med. 2006;355(22):2297-2307.

36. Sanyal AJ, et al. Pioglitazone, vitamin E, or placebo for nonalcoholic steatohepatitis. N Engl J Med. 2010;362(18):1675-1685

37. Thomas C, Pellicciari R, Pruzanski M, Auwerx J, Schoonjans K. Targeting bile-acid signalling for metabolic diseases. Nat Rev Drug Discov. 2008;7(8):678-693.

38. Verbeke L, et al. Obeticholic acid, a farnesoid X receptor agonist, improves portal hypertension by two distinct pathways in cirrhotic rats. Hepatology. 2014;59(6):2286-2298.

39. Thursz MR, Forrest EH, Ryder S, STOPAH investigators. Prednisolone or pentoxifylline for alcoholic hepatitis. $N$ Engl J Med. 2015;373(3):282-283.

40. Lakshman MR. Some novel insights into the pathogenesis of alcoholic steatosis. Alcohol. 2004;34(1):45-48.

41. Lakshman R, Shah R, Reyes-Gordillo K, Varatharajalu R. Synergy between NAFLD and AFLD and potential biomarkers. Clin Res Hepatol Gastroenterol. 2015;39(suppl 1):S29-S34.

42. Lin J, Handschin C, Spiegelman BM. Metabolic control through the PGC-1 family of transcription coactivators. Cell Metab. 2005;1(6):361-370.

43. You M, Fischer M, Deeg MA, Crabb DW. Ethanol induces fatty acid synthesis pathways by activation of sterol regulatory element-binding protein (SREBP). J Biol Chem. 2002;277(32):29342-29347.

44. You M, Liang X, Ajmo JM, Ness GC. Involvement of mammalian sirtuin 1 in the action of ethanol in the liver. Am J Physiol Gastrointest Liver Physiol. 2008;294(4):G892-G898.

45. Ji C, Chan C, Kaplowitz N. Predominant role of sterol response element binding proteins (SREBP) lipogenic pathways in hepatic steatosis in the murine intragastric ethanol feeding model. J Hepatol. 2006;45(5):717-724.

46. Mitsuyoshi $\mathrm{H}$, et al. Analysis of hepatic genes involved in the metabolism of fatty acids and iron in nonalcoholic fatty liver disease. Hepatol Res. 2009;39(4):366-373.

47. Higuchi $\mathrm{N}$, et al. Liver $\mathrm{X}$ receptor in cooperation with SREBP-1c is a major lipid synthesis regulator in nonalcoholic fatty liver disease. Hepatol Res. 2008;38(11):1122-1129.

48. Kohjima M, et al. SREBP-1c, regulated by the insulin and AMPK signaling pathways, plays a role in nonalcoholic fatty liver disease. Int J Mol Med. 2008;21(4):507-511.

49. You M, Matsumoto M, Pacold CM, Cho WK, Crabb DW. The role of AMP-activated protein kinase in the action of ethanol in the liver. Gastroenterology. 2004;127(6):1798-1808

50. Morgan K, et al. Altered expression of transcription factors and genes regulating lipogenesis in liver and adipose tissue of mice with high fat diet-induced obesity and nonalcoholic fatty liver disease. Eur J Gastroenterol Hepatol. 2008;20(9):843-854.

51. Staels B, et al. Hepatoprotective effects of the dual peroxisome proliferator-activated receptor $\alpha / \delta$ agonist, GFT505, in rodent models of nonalcoholic fatty liver disease/nonalcoholic steatohepatitis. Hepatology. 2013;58(6):1941-1952.

52. Harriman G, et al. Acetyl-CoA carboxylase inhibition by ND-630 reduces hepatic steatosis, improves insulin sensitivity, and modulates dyslipidemia in rats. Proc Natl Acad Sci U S A. 2016;113(13):E1796-E1805.

53. Scorletti E, et al. Effects of purified eicosapentaenoic and docosahexaenoic acids in nonalcoholic fatty liver disease: results from the Welcome* study. Hepatology. 2014;60(4):1211-1221.

54. Musso G, Cassader M, Gambino R. Non-alcoholic steatohepatitis: emerging molecular targets and therapeutic strategies. Nat Rev Drug Discov. 2016;15(4):249-274.

55. Choi CS, et al. Suppression of diacylglycerol acyltransferase-2 (DGAT2), but not DGAT1, with antisense oligonucleotides reverses diet-induced hepatic steatosis and insulin resistance. J Biol Chem. 2007;282(31):22678-22688.

56. Singh S, Allen AM, Wang Z, Prokop LJ, Murad MH, Loomba R. Fibrosis progression in nonalcoholic fatty liver vs nonalcoholic steatohepatitis: a systematic review and meta-analysis of paired-biopsy studies. Clin Gastroenterol Hepatol. 2015;13(4):643-54.e1.

57. Calzadilla Bertot L, Adams LA. The Natural Course of Non-Alcoholic Fatty Liver Disease. Int J Mol Sci. 2016;17(5):E774.

58. Li ZZ, Berk M, McIntyre TM, Feldstein AE. Hepatic lipid partitioning and liver damage in nonalcoholic fatty liver disease: role of stearoyl-CoA desaturase. J Biol Chem. 2009;284(9):5637-5644.

59. Yamaguchi K, et al. Inhibiting triglyceride synthesis improves hepatic steatosis but exacerbates liver damage and fibrosis in obese mice with nonalcoholic steatohepatitis. Hepatology. 2007;45(6):1366-1374.

60. Malhi H, Guicciardi ME, Gores GJ. Hepatocyte death: a clear and present danger. Physiol Rev. 2010;90(3):1165-1194.

61. Casey CA, Nanji A, Cederbaum AI, Adachi M, Takahashi T. Alcoholic liver disease and apoptosis. Alcohol Clin Exp Res. 2001;25(5 suppl ISBRA):49S-53S.

62. Feldstein AE, et al. Hepatocyte apoptosis and fas expression are prominent features of human nonalcoholic steatohepatitis. Gastroenterology. 2003;125(2):437-443.

63. Feldstein AE, Gores GJ. Apoptosis in alcoholic and nonalcoholic steatohepatitis. Front Biosci. 2005;10:3093-3099.

64. Guicciardi ME, Gores GJ. Life and death by death receptors. FASEB J. 2009;23(6):1625-1637.

65. Idrissova L, et al. TRAIL receptor deletion in mice suppresses the inflammation of nutrient excess. J Hepatol. 2015;62(5):1156-1163.

66. Affò S, et al. Transcriptome analysis identifies TNF superfamily receptors as potential therapeutic targets in alcoholic hepatitis. Gut. 2013;62(3):452-460.

67. Malhi H, Bronk SF, Werneburg NW, Gores GJ. Free fatty acids induce JNK-dependent hepatocyte lipoapoptosis. J Biol Chem. 2006;281(17):12093-12101.

68. Malhi H, Barreyro FJ, Isomoto H, Bronk SF, Gores GJ. Free fatty acids sensitise hepatocytes to TRAIL mediated cytotoxicity. Gut. 2007;56(8):1124-1131.

69. Cazanave SC, et al. Death receptor 5 signaling promotes hepatocyte lipoapoptosis. J Biol Chem. 2011;286(45):39336-39348.

70. Mundt B, et al. Tumour necrosis factor related apoptosis inducing ligand (TRAIL) induces hepatic steatosis in viral hepatitis 
and after alcohol intake. Gut. 2005;54(11):1590-1596.

71. Hirsova P, Gores GJ. Death receptor-mediated cell death and proinflammatory signaling in nonalcoholic steatohepatitis. Cell Mol Gastroenterol Hepatol. 2015;1(1):17-27.

72. Czabotar PE, Lessene G, Strasser A, Adams JM. Control of apoptosis by the BCL-2 protein family: implications for physiology and therapy. Nat Rev Mol Cell Biol. 2014;15(1):49-63.

73. Zhang W, et al. Tumor necrosis factor-alpha accelerates apoptosis of steatotic hepatocytes from a murine model of non-alcoholic fatty liver disease. Biochem Biophys Res Commun. 2010;391(4):1731-1736.

74. Yamamoto E, et al. Olmesartan prevents cardiovascular injury and hepatic steatosis in obesity and diabetes, accompanied by apoptosis signal regulating kinase-1 inhibition. Hypertension. 2008;52(3):573-580.

75. Lassailly G, Caiazzo R, Pattou F, Mathurin P. Perspectives on Treatment for Nonalcoholic Steatohepatitis. Gastroenterology. 2016;150(8):1835-1848.

76. Loomba R, Lawitz E, Mantry P, Jayakumar S. Abstract presented at: AASLD Liver Meeting; November 11-15, 2016; Boston, MA. https://www.aasld.org/sites/default/files/LBA\%20Full\%20Abstracts\%20Fina1\%20\%28Trimmed\%29_1.pdf. Accessed August 31, 2017.

77. Wang PX, et al. Targeting CASP8 and FADD-like apoptosis regulator ameliorates nonalcoholic steatohepatitis in mice and nonhuman primates. Nat Med. 2017;23(4):439-449.

78. Naveau S, et al. A double-blind randomized controlled trial of infliximab associated with prednisolone in acute alcoholic hepatitis. Hepatology. 2004;39(5):1390-1397.

79. Boetticher NC, et al. A randomized, double-blinded, placebo-controlled multicenter trial of etanercept in the treatment of alcoholic hepatitis. Gastroenterology. 2008;135(6):1953-1960.

80. Akerman P, et al. Antibodies to tumor necrosis factor-alpha inhibit liver regeneration after partial hepatectomy. Am J Physiol. 1992;263(4 Pt 1):G579-G585.

81. Czabotar PE, Murphy JM. A tale of two domains - a structural perspective of the pseudokinase, MLKL. FEBS J. 2015;282(22):4268-4278.

82. He S, et al. Receptor interacting protein kinase-3 determines cellular necrotic response to TNF- $\alpha$. Cell. 2009;137(6):1100-1111.

83. Degterev A, et al. Chemical inhibitor of nonapoptotic cell death with therapeutic potential for ischemic brain injury. Nat Chem Biol. 2005;1(2):112-119.

84. Cho YS, et al. Phosphorylation-driven assembly of the RIP1-RIP3 complex regulates programmed necrosis and virus-induced inflammation. Cell. 2009;137(6):1112-1123.

85. Roychowdhury S, McMullen MR, Pisano SG, Liu X, Nagy LE. Absence of receptor interacting protein kinase 3 prevents ethanol-induced liver injury. Hepatology. 2013;57(5):1773-1783.

86. Gautheron J, et al. A positive feedback loop between RIP3 and JNK controls non-alcoholic steatohepatitis. EMBO Mol Med. 2014;6(8):1062-1074.

87. Hatting M, et al. Hepatocyte caspase-8 is an essential modulator of steatohepatitis in rodents. Hepatology. 2013;57(6):2189-2201.

88. Dara L, Liu ZX, Kaplowitz N. Questions and controversies: the role of necroptosis in liver disease. Cell Death Discov. 2016;2:16089.

89. Cursio R, Colosetti P, Codogno P, Cuervo AM, Shen HM. The role of autophagy in liver diseases: mechanisms and potential therapeutic targets. Biomed Res Int. 2015;2015:480508.

90. Ratziu V, et al. A randomized controlled trial of high-dose ursodesoxycholic acid for nonalcoholic steatohepatitis. $J$ Hepatol. 2011;54(5):1011-1019.

91. Lindor KD, et al. Ursodeoxycholic acid for treatment of nonalcoholic steatohepatitis: results of a randomized trial. Hepatology. 2004;39(3):770-778.

92. Miller ER, Pastor-Barriuso R, Dalal D, Riemersma RA, Appel LJ, Guallar E. Meta-analysis: high-dosage vitamin E supplementation may increase all-cause mortality. Ann Intern Med. 2005;142(1):37-46.

93. Klein EA, et al. Vitamin E and the risk of prostate cancer: the Selenium and Vitamin E Cancer Prevention Trial (SELECT) JAMA. 2011;306(14):1549-1556.

94. Adachi Y, Bradford BU, Gao W, Bojes HK, Thurman RG. Inactivation of Kupffer cells prevents early alcohol-induced liver injury. Hepatology. 1994;20(2):453-460.

95. Lanthier N, Molendi-Coste O, Cani PD, van Rooijen N, Horsmans Y, Leclercq IA. Kupffer cell depletion prevents but has no therapeutic effect on metabolic and inflammatory changes induced by a high-fat diet. FASEB J. 2011;25(12):4301-4311.

96. Seo YS, et al. HMGB1 recruits hepatic stellate cells and liver endothelial cells to sites of ethanol-induced parenchymal cell injury. Am J Physiol Gastrointest Liver Physiol. 2013;305(11):G838-G848.

97. Li L, et al. Nuclear factor high-mobility group box1 mediating the activation of Toll-like receptor 4 signaling in hepatocytes in the early stage of nonalcoholic fatty liver disease in mice. Hepatology. 2011;54(5):1620-1630.

98. Huebener P, et al. High-mobility group box 1 is dispensable for autophagy, mitochondrial quality control, and organ function in vivo. Cell Metab. 2014;19(3):539-547.

99. Guy CD, et al. Hedgehog pathway activation parallels histologic severity of injury and fibrosis in human nonalcoholic fatty liver disease. Hepatology. 2012;55(6):1711-1721.

100. Hirsova P, Ibrahim SH, Bronk SF, Yagita H, Gores GJ. Vismodegib suppresses TRAIL-mediated liver injury in a mouse model of nonalcoholic steatohepatitis. PLoS One. 2013;8(7):e70599.

101. Ibrahim SH, et al. Mixed lineage kinase 3 mediates release of C-X-C motif ligand 10-bearing chemotactic extracellular vesicles from lipotoxic hepatocytes. Hepatology. 2016;63(3):731-744

102. Verma VK, et al. Alcohol stimulates macrophage activation through caspase-dependent hepatocyte derived release of CD40L containing extracellular vesicles. J Hepatol. 2016;64(3):651-660.

103. Kakazu E, Mauer AS, Yin M, Malhi H. Hepatocytes release ceramide-enriched pro-inflammatory extracellular vesicles in an IRE1 $\alpha$-dependent manner. J Lipid Res. 2016;57(2):233-245.

104. Saha B, Momen-Heravi F, Kodys K, Szabo G. MicroRNA cargo of extracellular vesicles from alcohol-exposed monocytes sig nals naive monocytes to differentiate into M2 macrophages. J Biol Chem. 2016;291(1):149-159. 
105. Hirsova P, et al. Lipid-induced signaling causes release of inflammatory extracellular vesicles from hepatocytes. Gastroenterology. 2016;150(4):956-967.

106. Mauer AS, Hirsova P, Maiers JL, Shah VH, Malhi H. Inhibition of sphingosine 1-phosphate signaling ameliorates murine nonalcoholic steatohepatitis. Am J Physiol Gastrointest Liver Physiol. 2017;312(3):G300-G313.

107. Ramaiah SK, Jaeschke H. Role of neutrophils in the pathogenesis of acute inflammatory liver injury. Toxicol Pathol. 2007;35(6):757-766.

108. Altamirano J, et al. A histologic scoring system for prognosis of patients with alcoholic hepatitis. Gastroenterology. 2014;146(5):1231-9.e1.

109. Taïeb J, et al. Polymorphonuclear neutrophils are a source of hepatocyte growth factor in patients with severe alcoholic hepatitis. J Hepatol. 2002;36(3):342-348.

110. Talukdar S, et al. Neutrophils mediate insulin resistance in mice fed a high-fat diet through secreted elastase. Nat Med. 2012;18(9):1407-1412.

111. Mandrekar P, Ambade A, Lim A, Szabo G, Catalano D. An essential role for monocyte chemoattractant protein-1 in alcoholic liver injury: regulation of proinflammatory cytokines and hepatic steatosis in mice. Hepatology. 2011;54(6):2185-2197.

112. Connolly MK, et al. In hepatic fibrosis, liver sinusoidal endothelial cells acquire enhanced immunogenicity. J Immunol. 2010;185(4):2200-2208.

113. Sprenger H, Kaufmann A, Garn H, Lahme B, Gemsa D, Gressner AM. Differential expression of monocyte chemotactic protein-1 (MCP-1) in transforming rat hepatic stellate cells. J Hepatol. 1999;30(1):88-94.

114. Miura K, Yang L, van Rooijen N, Ohnishi H, Seki E. Hepatic recruitment of macrophages promotes nonalcoholic steatohepatitis through CCR2. Am J Physiol Gastrointest Liver Physiol. 2012;302(11):G1310-G1321.

115. Seki E, et al. CCR1 and CCR5 promote hepatic fibrosis in mice. J Clin Invest. 2009;119(7):1858-1870

116. Berres ML, et al. Antagonism of the chemokine Ccl5 ameliorates experimental liver fibrosis in mice. J Clin Invest. 2010;120(11):4129-4140.

117. Friedman S, et al. Efficacy and safety study of cenicriviroc for the treatment of non-alcoholic steatohepatitis in adult subjects with liver fibrosis: CENTAUR Phase 2b study design. Contemp Clin Trials. 2016;47:356-365.

118. 118. Arun S, et al. Abstract presented at: AASLD Liver Meeting; November 11-15, 2016; Boston, MA. https://www.aasld org/sites/default/files/LBA\%20Full\%20Abstracts\%20Fina1\%20\%28Trimmed\%29_1.pdf. Accessed August 31, 2017.

119. Mehal WZ, Schuppan D. Antifibrotic therapies in the liver. Semin Liver Dis. 2015;35(2):184-198.

120. Thompson JE, et al. A fully human antibody neutralising biologically active human TGFbeta2 for use in therapy. J Immunol Methods. 1999;227(1-2):17-29.

121. Mori Y, Ishida W, Bhattacharyya S, Li Y, Platanias LC, Varga J. Selective inhibition of activin receptor-like kinase 5 signaling blocks profibrotic transforming growth factor $\beta$ responses in skin fibroblasts. Arthritis Rheum. 2004;50(12):4008-4021.

122. Ueno $\mathrm{H}$, et al. A soluble transforming growth factor beta receptor expressed in muscle prevents liver fibrogenesis and dysfunction in rats. Hum Gene Ther. 2000;11(1):33-42.

123. Yata Y, Gotwals P, Koteliansky V, Rockey DC. Dose-dependent inhibition of hepatic fibrosis in mice by a TGF- $\beta$ soluble receptor: implications for antifibrotic therapy. Hepatology. 2002;35(5):1022-1030.

124. Vogt J, Traynor R, Sapkota GP. The specificities of small molecule inhibitors of the TGF $\beta$ and BMP pathways. Cell Signal. 2011;23(11):1831-1842.

125. Samarakoon R, Overstreet JM, Higgins PJ. TGF- $\beta$ signaling in tissue fibrosis: redox controls, target genes and therapeutic opportunities. Cell Signal. 2013;25(1):264-268.

126. Henderson NC, et al. Targeting of $\alpha \mathrm{v}$ integrin identifies a core molecular pathway that regulates fibrosis in several organs. Nat Med. 2013;19(12):1617-1624.

127. Barry-Hamilton V, et al. Allosteric inhibition of lysyl oxidase-like-2 impedes the development of a pathologic microenvironment. Nat Med. 2010;16(9):1009-1017.

128. Verdelho Machado M, Diehl AM. Role of Hedgehog Signaling Pathway in NASH. Int J Mol Sci. 2016;17(6):E857.

129. Choi SS, et al. Hedgehog pathway activation and epithelial-to-mesenchymal transitions during myofibroblastic transformation of rat hepatic cells in culture and cirrhosis. Am J Physiol Gastrointest Liver Physiol. 2009;297(6):G1093-G1106.

130.Xie G, et al. Cross-talk between Notch and Hedgehog regulates hepatic stellate cell fate in mice. Hepatology. 2013;58(5):1801-1813.

131. Turnbaugh PJ, Gordon JI. The core gut microbiome, energy balance and obesity. J Physiol (Lond). 2009;587(Pt 17):4153-4158.

132. Betrapally NS, Gillevet PM, Bajaj JS. Changes in the intestinal microbiome and alcoholic and nonalcoholic liver diseases: causes or effects? Gastroenterology. 2016;150(8):1745-1755.e3.

133. Yang AM, et al. Intestinal fungi contribute to development of alcoholic liver disease. J Clin Invest. 2017;127(7):2829-2841.

134. Bala S, Marcos M, Gattu A, Catalano D, Szabo G. Acute binge drinking increases serum endotoxin and bacterial DNA levels in healthy individuals. PLoS One. 2014;9(5):e96864.

135. Rivera CA, Bradford BU, Seabra V, Thurman RG. Role of endotoxin in the hypermetabolic state after acute ethanol exposure. Am J Physiol. 1998;275(6 pt 1):G1252-G1258.

136. Mutlu EA, et al. Colonic microbiome is altered in alcoholism. Am J Physiol Gastrointest Liver Physiol. 2012;302(9):G966-G978.

137. Fukui H, Brauner B, Bode JC, Bode C. Plasma endotoxin concentrations in patients with alcoholic and non-alcoholic liver disease: reevaluation with an improved chromogenic assay. J Hepatol. 1991;12(2):162-169.

138. Roh YS, Seki E. Toll-like receptors in alcoholic liver disease, non-alcoholic steatohepatitis and carcinogenesis. J Gastroenterol Hepatol. 2013;28(suppl 1):38-42.

139. Neish AS. Microbes in gastrointestinal health and disease. Gastroenterology. 2009;136(1):65-80.

140. Zhu L, et al. Characterization of gut microbiomes in nonalcoholic steatohepatitis (NASH) patients: a connection between endogenous alcohol and NASH. Hepatology. 2013;57(2):601-609.

141. Petrasek J, Csak T, Ganz M, Szabo G. Differences in innate immune signaling between alcoholic and non-alcoholic steatohepatitis. J Gastroenterol Hepatol. 2013;28(suppl 1):93-98.

142. Mandal P, Roychowdhury S, Park PH, Pratt BT, Roger T, Nagy LE. Adiponectin and heme oxygenase-1 suppress TLR4/MyD88-independent signaling in rat Kupffer cells and in mice after chronic ethanol exposure. J Immunol. 2010;185(8):4928-4937. 
143. Alisi A, et al. Randomised clinical trial: The beneficial effects of VSL\#3 in obese children with non-alcoholic steatohepatitis. Aliment Pharmacol Ther. 2014;39(11):1276-1285.

144. Li Z, et al. Probiotics and antibodies to TNF inhibit inflammatory activity and improve nonalcoholic fatty liver disease. Hepatology. 2003;37(2):343-350

145. Swann JR, et al. Systemic gut microbial modulation of bile acid metabolism in host tissue compartments. Proc Natl Acad Sci US A. 2011;108(suppl 1):4523-4530.

146. Wong VW, et al. Treatment of nonalcoholic steatohepatitis with probiotics. A proof-of-concept study. Ann Hepatol. 2013;12(2):256-262.

147. Kirpich IA, et al. Probiotics restore bowel flora and improve liver enzymes in human alcohol-induced liver injury: a pilot study. Alcohol. 2008;42(8):675-682.

148. Solga SF, Buckley G, Clark JM, Horska A, Diehl AM. The effect of a probiotic on hepatic steatosis. J Clin Gastroenterol. 2008;42(10):1117-1119.

149. Philips CA, et al. Healthy donor fecal microbiota transplantation in steroid-ineligible severe alcoholic hepatitis: A Pilot Study. Clin Gastroenterol Hepatol. 2017;15(4):600-602.

150. Donnelly KL, Smith CI, Schwarzenberg SJ, Jessurun J, Boldt MD, Parks EJ. Sources of fatty acids stored in liver and secreted via lipoproteins in patients with nonalcoholic fatty liver disease. J Clin Invest. 2005;115(5):1343-1351.

151. Bays H. Adiposopathy, "sick fat," Ockham's razor, and resolution of the obesity paradox. Curr Atheroscler Rep. 2014;16(5):409.

152. Begriche K, Massart J, Robin MA, Bonnet F, Fromenty B. Mitochondrial adaptations and dysfunctions in nonalcoholic fatty liver disease. Hepatology. 2013;58(4):1497-1507.

153. Brady LJ, Brady PS, Romsos DR, Hoppel CL. Elevated hepatic mitochondrial and peroxisomal oxidative capacities in fed and starved adult obese (ob/ob) mice. Biochem J. 1985;231(2):439-444

154. Cortez-Pinto H, Chatham J, Chacko VP, Arnold C, Rashid A, Diehl AM. Alterations in liver ATP homeostasis in human nonalcoholic steatohepatitis: a pilot study. JAMA. 1999;282(17):1659-1664.

155. Serviddio G, et al. Uncoupling protein-2 (UCP2) induces mitochondrial proton leak and increases susceptibility of non-alcoholic steatohepatitis (NASH) liver to ischaemia-reperfusion injury. Gut. 2008;57(7):957-965.

156. Yang Y, Jiang G, Zhang P, Fan J. Programmed cell death and its role in inflammation. Mil Med Res. 2015;2:12.

157. Gruben N, Shiri-Sverdlov R, Koonen DP, Hofker MH. Nonalcoholic fatty liver disease: A main driver of insulin resistance or a dangerous liaison? Biochim Biophys Acta. 2014;1842(11):2329-2343.

158. Wisely GB, et al. Hepatocyte nuclear factor 4 is a transcription factor that constitutively binds fatty acids. Structure. 2002;10(9):1225-1234.

159. Miura K, Ohnishi H. Role of gut microbiota and Toll-like receptors in nonalcoholic fatty liver disease. World J Gastroenterol. 2014;20(23):7381-7391.

160. Ashraf NU, Sheikh TA. Endoplasmic reticulum stress and Oxidative stress in the pathogenesis of Non-alcoholic fatty liver disease. Free Radic Res. 2015;49(12):1405-1418.

161. Amir M, Czaja MJ. Autophagy in nonalcoholic steatohepatitis. Expert Rev Gastroenterol Hepatol. 2011;5(2):159-166.

162. Wei X, et al. Chronic alcohol exposure disturbs lipid homeostasis at the adipose tissue-liver axis in mice: analysis of triacylglycerols using high-resolution mass spectrometry in combination with in vivo metabolite deuterium labeling. PLoS One. 2013;8(2):e55382.

163. Lassailly G, et al. Bariatric Surgery Reduces Features of Nonalcoholic Steatohepatitis in Morbidly Obese Patients. Gastroenterology. 2015;149(2):379-388; quiz e15.

164. Zhang $\mathrm{Y}$, et al. The link between fibroblast growth factor 21 and sterol regulatory element binding protein 1c during lipogenesis in hepatocytes. Mol Cell Endocrinol. 2011;342(1-2):41-47.

165. Lee J, et al. Exendin-4 regulates lipid metabolism and fibroblast growth factor 21 in hepatic steatosis. Metab Clin Exp. 2014;63(8):1041-1048.

166. Li K, Li L, Yang M, Liu H, Boden G, Yang G. The effects of fibroblast growth factor-21 knockdown and over-expression on its signaling pathway and glucose-lipid metabolism in vitro. Mol Cell Endocrinol. 2012;348(1):21-26.

167. Chen W, et al. Growth hormone induces hepatic production of fibroblast growth factor 21 through a mechanism dependent on lipolysis in adipocytes. J Biol Chem. 2011;286(40):34559-34566.

168. Liu J, Xu Y, Hu Y, Wang G. The role of fibroblast growth factor 21 in the pathogenesis of non-alcoholic fatty liver disease and implications for therapy. Metab Clin Exp. 2015;64(3):380-390.

169. Lin Z, et al. Adiponectin mediates the metabolic effects of FGF21 on glucose homeostasis and insulin sensitivity in mice. Cell Metab. 2013;17(5):779-789.

170. Camporez JP, et al. Cellular mechanisms by which FGF21 improves insulin sensitivity in male mice. Endocrinology. 2013;154(9):3099-3109.

171. Mu J, et al. FGF21 analogs of sustained action enabled by orthogonal biosynthesis demonstrate enhanced antidiabetic pharmacology in rodents. Diabetes. 2012;61(2):505-512.

172. Xu J, et al. Fibroblast growth factor 21 reverses hepatic steatosis, increases energy expenditure, and improves insulin sensitivity in diet-induced obese mice. Diabetes. 2009;58(1):250-259.

173. Marchesini G, et al. Nonalcoholic fatty liver, steatohepatitis, and the metabolic syndrome. Hepatology. 2003;37(4):917-923.

174. Jou J, Choi SS, Diehl AM. Mechanisms of disease progression in nonalcoholic fatty liver disease. Semin Liver Dis. 2008;28(4):370-379.

175. Kershaw EE, Flier JS. Adipose tissue as an endocrine organ. J Clin Endocrinol Metab. 2004;89(6):2548-2556.

176. Wajant H, Pfizenmaier K, Scheurich P. Tumor necrosis factor signaling. Cell Death Differ. 2003;10(1):45-65.

177. Monetti M, et al. Dissociation of hepatic steatosis and insulin resistance in mice overexpressing DGAT in the liver. Cell Metab. 2007;6(1):69-78.

178. Carr RM, Correnti J. Insulin resistance in clinical and experimental alcoholic liver disease. Ann N Y Acad Sci. 2015;1353:1-20.

179. Kang L, et al. Chronic ethanol and triglyceride turnover in white adipose tissue in rats: inhibition of the anti-lipolytic action of insulin after chronic ethanol contributes to increased triglyceride degradation. J Biol Chem. 2007;282(39):28465-28473. 
180. Sun X, et al. Activation of peroxisome proliferator-activated receptor- $\gamma$ by rosiglitazone improves lipid homeostasis at the adipose tissue-liver axis in ethanol-fed mice. Am J Physiol Gastrointest Liver Physiol. 2012;302(5):G548-G557.

181. Aithal GP, et al. Randomized, placebo-controlled trial of pioglitazone in nondiabetic subjects with nonalcoholic steatohepatitis. Gastroenterology. 2008;135(4):1176-1184.

182. Ratziu V, et al. Rosiglitazone for nonalcoholic steatohepatitis: one-year results of the randomized placebo-controlled Fatty Liver Improvement with Rosiglitazone Therapy (FLIRT) Trial. Gastroenterology. 2008;135(1):100-110.

183. Rakoski MO, Singal AG, Rogers MA, Conjeevaram H. Meta-analysis: insulin sensitizers for the treatment of non-alcoholic steatohepatitis. Aliment Pharmacol Ther. 2010;32(10):1211-1221.

184. Machado MV, Cortez-Pinto H. Nuclear receptors: how do they position in non-alcoholic fatty liver disease treatment? Liver Int. 2014;34(9):1291-1294.

185. Chawla A, Repa JJ, Evans RM, Mangelsdorf DJ. Nuclear receptors and lipid physiology: opening the X-files. Science. 2001;294(5548):1866-1870.

186. Wang H, LeCluyse EL. Role of orphan nuclear receptors in the regulation of drug-metabolising enzymes. Clin Pharmacokinet. 2003;42(15):1331-1357.

187. Yu S, Rao S, Reddy JK. Peroxisome proliferator-activated receptors, fatty acid oxidation, steatohepatitis and hepatocarcinogenesis. Curr Mol Med. 2003;3(6):561-572.

188. Gyamfi MA, Wan YJ. Pathogenesis of alcoholic liver disease: the role of nuclear receptors. Exp Biol Med (Maywood). 2010;235(5):547-560.

189. Abdelmegeed MA, Yoo SH, Henderson LE, Gonzalez FJ, Woodcroft KJ, Song BJ. PPARalpha expression protects male mice from high fat-induced nonalcoholic fatty liver. J Nutr. 2011;141(4):603-610.

190. Lefebvre P, Cariou B, Lien F, Kuipers F, Staels B. Role of bile acids and bile acid receptors in metabolic regulation. Physiol Rev. 2009;89(1):147-191.

191. Mudaliar S, et al. Efficacy and safety of the farnesoid X receptor agonist obeticholic acid in patients with type 2 diabetes and nonalcoholic fatty liver disease. Gastroenterology. 2013;145(3):574-82.e1.

192. Wagner M, Zollner G, Trauner M. Nuclear receptors in liver disease. Hepatology. 2011;53(3):1023-1034.

193. Adorini L, Pruzanski M, Shapiro D. Farnesoid X receptor targeting to treat nonalcoholic steatohepatitis. Drug Discov Today. 2012;17(17-18):988-997.

194. Naugler WE, et al. Fibroblast growth factor signaling controls liver size in mice with humanized livers. Gastroenterology. 2015;149(3):728-40.e15.

195. Avila MA, Moschetta A. The FXR-FGF19 gut-liver axis as a novel "Hepatostat". Gastroenterology. 2015;149(3):537-540.

196. Schreuder TC, et al. The hepatic response to FGF19 is impaired in patients with nonalcoholic fatty liver disease and insulin resistance. Am J Physiol Gastrointest Liver Physiol. 2010;298(3):G440-G445.

197. Szabo G, Iracheta-Vellve A. Inflammasome activation in the liver: focus on alcoholic and non-alcoholic steatohepatitis. Clin Res Hepatol Gastroenterol. 2015;39(suppl 1):S18-S23.

198. Franchi L, Eigenbrod T, Núñez G. Cutting edge: TNF- $\alpha$ mediates sensitization to ATP and silica via the NLRP3 inflammasome in the absence of microbial stimulation. J Immunol. 2009;183(2):792-796.

199. Bauernfeind FG, et al. Cutting edge: NF-kB activating pattern recognition and cytokine receptors license NLRP3 inflammasome activation by regulating NLRP3 expression. J Immunol. 2009;183(2):787-791.

200. Stehlik C, et al. The PAAD/PYRIN-family protein ASC is a dual regulator of a conserved step in nuclear factor $\mathrm{\kappa B}$ activation pathways. J Exp Med. 2002;196(12):1605-1615.

201. Stehlik C, Lee SH, Dorfleutner A, Stassinopoulos A, Sagara J, Reed JC. Apoptosis-associated speck-like protein containing a caspase recruitment domain is a regulator of procaspase-1 activation. J Immunol. 2003;171(11):6154-6163.

202. Ganz M, Csak T, Nath B, Szabo G. Lipopolysaccharide induces and activates the Nalp3 inflammasome in the liver. World J Gas troenterol. 2011;17(43):4772-4778.

203. Lippai D, et al. Alcohol-induced IL-1 $\beta$ in the brain is mediated by NLRP3/ASC inflammasome activation that amplifies neuroinflammation. J Leukoc Biol. 2013;94(1):171-182.

204. Ganz M, Szabo G. Immune and inflammatory pathways in NASH. Hepatol Int. 2013;7(suppl 2):771-781.

205. Kamari Y, et al. Lack of interleukin- $1 \alpha$ or interleukin-1 $\beta$ inhibits transformation of steatosis to steatohepatitis and liver fibrosis in hypercholesterolemic mice. J Hepatol. 2011;55(5):1086-1094.

206. Derdak Z, Villegas KA, Harb R, Wu AM, Sousa A, Wands JR. Inhibition of p53 attenuates steatosis and liver injury in a mouse model of non-alcoholic fatty liver disease. J Hepatol. 2013;58(4):785-791.

207. Jin X, Chen YP, Kong M, Zheng L, Yang YD, Li YM. Transition from hepatic steatosis to steatohepatitis: unique microRNA patterns and potential downstream functions and pathways. J Gastroenterol Hepatol. 2012;27(2):331-340.

208. Yin H, Hu M, Zhang R, Shen Z, Flatow L, You M. MicroRNA-217 promotes ethanol-induced fat accumulation in hepatocytes by down-regulating SIRT1. J Biol Chem. 2012;287(13):9817-9826.

209. Miyaaki H, et al. Significance of serum and hepatic microRNA-122 levels in patients with non-alcoholic fatty liver disease. Liver Int. 2014;34(7):e302-e307.

210. Roderburg C, et al. Micro-RNA profiling reveals a role for miR-29 in human and murine liver fibrosis. Hepatology. 2011;53(1):209-218

211. Pirola CJ, et al. Circulating microRNA signature in non-alcoholic fatty liver disease: from serum non-coding RNAs to liver histology and disease pathogenesis. Gut. 2015;64(5):800-812.

212. Banaudha K, et al. MicroRNA silencing of tumor suppressor DLC-1 promotes efficient hepatitis $C$ virus replication in primary human hepatocytes. Hepatology. 2011;53(1):53-61.

213. Szabo G, Satishchandran A. MicroRNAs in alcoholic liver disease. Semin Liver Dis. 2015;35(1):36-42.

214. Cheung $\mathrm{O}$, et al. Nonalcoholic steatohepatitis is associated with altered hepatic MicroRNA expression. Hepatology. 2008;48(6):1810-1820.

215. Szabo G, Bala S. MicroRNAs in liver disease. Nat Rev Gastroenterol Hepatol. 2013;10(9):542-552.

216. Janssen HL, et al. Treatment of HCV infection by targeting microRNA. N Engl J Med. 2013;368(18):1685-1694. 
217. Czech MP, Aouadi M, Tesz GJ. RNAi-based therapeutic strategies for metabolic disease. Nat Rev Endocrinol. 2011;7(8):473-484 218. Szabo G, Sarnow P, Bala S. MicroRNA silencing and the development of novel therapies for liver disease. $J$ Hepatol. 2012;57(2):462-466

219. Singh V, Sharma AK, Narasimhan RL, Bhalla A, Sharma N, Sharma R. Granulocyte colony-stimulating factor in severe alcoholic hepatitis: a randomized pilot study. Am J Gastroenterol. 2014;109(9):1417-1423.

220. Wong VW, et al. Community-based lifestyle modification programme for non-alcoholic fatty liver disease: a randomized controlled trial. J Hepatol. 2013;59(3):536-542. 